

Référence bibliographique :

Christian Gilot, "La politesse que donne l'usage du monde", lieuxdits\#1, juin 2011, pp.22-23. 


\title{
La politesse que donne l'usage du monde
}

\section{Christian Gilot}

\author{
II nous arrive parfois de ne pas reconnaître un visage qui pourtant \\ nous était familier. Parce qu'il a changé. Et si c'était l'inverse ? Nos \\ séparations s'annonceraient ainsi : j'ai tellement changé, je ne te \\ connais plus.
}

Et pour la ville? On peut s'éloigner de certains bâtiments et se détourner de quartiers entiers - parce que nous avons changé et ne les connaissons plus. Ayant peu de patience pour que nos yeux changent encore, nous tranchons alors, déchirant nos cités en fossés de poussières.

Mais leur résistance est inattendue : il serait léger de penser qu'il suffirait de remplacer chacun de ses bâtiments pour qu'une ville comme Amsterdam s'efface et se noie tout entière dans l'épaisseur de son passé.

Plusieurs niveaux d'invention se superposent en effet dans la ville voilà ce qui garantit que les choses étrangères puissent s'y côtoyer. Les choses et les gens. L'urbanité : la politesse que donne l'usage du monde qui s'annonçait dans les dictionnaires anciens.

Plusieurs niveaux se superposent : nous aurons des vases, des fleurs et des bouquets. Plusieurs niveaux d'invention : nous aurons des bateaux dans nos ports, des bannières accrochées aux mâts de nos beffrois, des prières arrachées aux croix de nos effrois. Plusieurs niveaux d'invention : des villes, des avenues et des maisons.

En ce sens, est-ce ses dessins ou bien la ville elle-même que désignait Giacometti dans son dernier ouvrage : Paris sans fin? 




